\title{
Emergence of methicillin-resistant Staphylococcus aureus from clonal complex 398 with no livestock association in Brazil
}

\author{
Egidio Domingos André Neto ${ }^{1}$, Renata Freire Alves Pereira ${ }^{1,3}{ }^{+}$, \\ Robert Eugene Snyder, ${ }^{1,4}$, Thamiris Santana Machado, ${ }^{1,5}$, Lialyz Soares Pereira André1, \\ Claudete Aparecida Araújo Cardoso ${ }^{2,5}$, Fábio Aguiar-Alves ${ }^{1,5}$
}

\author{
${ }^{1}$ Universidade Federal Fluminense, Laboratóro Universitário Rodolfo Albino, Laboratório de Epidemiologia e Biotecnologia Molecular, \\ Niterói, RJ, Brasil \\ ${ }^{2}$ Universidade Federal Fluminense, Faculdade de Medicina, Departmento Materno-Infantil, Niterói, RJ, Brasil \\ ${ }^{3}$ Universidade Federal Fluminense, Instituto de Biologia, Programa de Pós-Graduação em Ciência e Biotecnologia, Niterói, RJ, Brasil \\ ${ }^{4}$ University of California, School of Public Health, Division of Epidemiology, Berkeley, California, USA \\ ${ }^{5}$ Universidade Federal Fluminense, Escola de Medicina, Programa de Pós-Graduação em Patologia, Niterói, RJ, Brasil
}

CC398 is a livestock-associated Staphylococcus aureus. However, it has also been isolated from humans with no previous contact with livestock. A surveillance of methicillin-resistant $S$. aureus colonisation among children attending public day care centres and hospitals in Niterói and Rio de Janeiro, Brazil, between 2011 and 2013, resulted in the isolation of six cases of CC398 from individuals with no previous exposure to livestock. These isolates showed a high frequency of the $\operatorname{erm}(\mathrm{C})$ gene $(4 / 6,66.7 \%)$ with induced resistance to clindamycin, and a relatively high frequency of $S E$ s and $l u k S / l u k F$ genes. These results suggest the emergence of a non-LA-CC398 in Brazil.

Key words: MRSA - CC398 - genotyping

Staphylococcus aureus colonisation is the main risk factor for subsequent infection, and this risk is higher if the staphylococci are methicillin-resistant (MRSA) (Safdar \& Bradley 2008). Children experience particularly high rates of morbidity and mortality from staphylococcal infections (Iwamoto et al. 2013).

Clonal Complex 398 (CC398) is among the most important livestock-associated (LA) S. aureus genotypes, and contact with animals is a well-described risk factor for its colonisation or infection in humans (Smith \& Wardyn 2015). However, recent studies have described a non-LA-CC398 lineage in humans with no previous contact with livestock (Uhlemann et al. 2012, Larsen et al. 2015, Smith \& Wardyn 2015). This lineage has rapidly spread in humans over a wide-ranging geographical area, in particular in Europe and North America, and has been linked to invasive infection where it has been reported. These $S$. aureus isolates usually carry spa type t571 or t1451 (Valentin-Domelier et al. 2011, Uhlemann et al. 2012, Larsen et al. 2015, Smith \& Wardyn 2015).

In Brazil, as in all of Latin America, formal, integrated, or systematic $S$. aureus epidemiological surveillance systems are almost universally absent. To date, only three cases of CC398 have been reported in Brazil. The first was an MRSA isolate from a healthy dairy cow (staphylococcal protein A type t011) from a farm in the state of São Paulo (Silva et al. 2014), the second was an MSSA isolate that led to fatal pneumonia in a cancer pa-

doi: 10.1590/0074-02760170040

+Corresponding author: renatafreireapereira@gmail.com

Received 1 February 2017

Accepted 15 April 2017 tient in São Paulo (t034) (Gales et al. 2015) and the most recent was a case of an MRSA that was isolated from a patient with cystic fibrosis who had previous contact with farm animals (Lima et al. 2017). In South America, outside of Brazil, CC398 has also been reported in Colombia, also resulting in the death of the patient (Jiménez et al. 2011), and Peru, where it was isolated from several pigs at a commercial farm (Arriola et al. 2011).

Here, we report six cases of nasal colonisation by MRSA CC398 among children without any previous exposure to traditional CC398 risk factors (living in or having recently travelled to rural areas, or having recent contact with farm animals or livestock) between August 2011 and March 2016 in the cities of Niterói and Rio de Janeiro, Brazil.

The six CC398 bacterial isolates were identified from nasal swabs of 1852 children sampled in four different settings, including both outpatient and inpatient clinics, and 23 daycare centres. Four CC398 isolates were identified from a sampling of 500 children at two public inpatient clinics, while two were identified among 852 children reporting to paediatric outpatient clinics at two public hospitals. There were no children colonised with CC398 among the 500 sampled at 23 different daycare centres. All children attending the study sites during the period, whose parents agreed to the terms, were included in the study.

A total of 1852 nasal swab samples were collected in the cities of Niterói and Rio de Janeiro between 2011 and 2016 from children in five independent MRSA surveillance studies, in day care centres and public hospitals. The samples were submitted for laboratory testing of catalase and coagulase, plating in mannitol, antibiogram generation and for polymerase chain reaction (PCR) of the mecA gene, to identify MRSA samples. All 179 identified MRSAs were genotyped by PCR, multiplex-PCR (Oliveira \& de Lencastre 2002), spa-Typing (staphylococ- 
cal protein A typing) (Shopsin et al. 1999) and Multi-locus sequence type (MLST) methods (Enright et al. 2000). Six were identified as ST398 by MLST. Five had the t1451 spa type and one was t1985. Five carried the SCCmec IV and one the SCCmec V. All six CC398 strains were non-typeable by PFGE with SmaI, corroborating previous reports (Larsen et al. 2015, Smith \& Wardyn 2015). The species specificity of all isolates was confirmed by a positive PCR reaction for both the $S A 442$ and $f e m A$ genes.

Antimicrobial susceptibility was performed with 14 antimicrobial disks (oxacillin, cefoxitin, penicillin, ciprofloxacin, chloramphenicol, clindamycin, erythromycin, nitrofurantoin, gentamicin, rifanpicin, trimethoprim, sulfamethoxazole, tetracycline and vancomycin) according to The Clinical and Laboratory Standards Institute guidelines (CLSI 2015), and resistant isolates were subjected to PCR for the identification of resistance genes. Four isolates were resistant to erythromycin $(4 / 6$, $66.7 \%$ ), with all six $(100 \%)$ demonstrating an induced resistance to clindamycin (D-test positivity) that was encoded by the $\operatorname{erm}(\mathrm{C})$ gene. One isolate was resistant to trimethoprim/sulfamethoxazole $(1 / 6,16.7 \%)$. This was confirmed by PCR of the $d f r \mathrm{G}$ gene.

PCR was used to confirm the presence of genes encoding staphylococcal enterotoxins (SEs) (sea, seb, sec, sed, see, seg, seh, sei, selj, selk, sell, selm, seln, selo, selp, selq, selr and tst 1 ) and lukS/lukF, encoding Panton-Valentine leukocidin (PVL). All isolates carried multiple SE genes (Table), and three (50\%) were PVL-positive (Lina et al. 1999, Omoe et al. 2005).

All six CC398 carriers resided in the urban centre or suburban periphery of Rio de Janeiro, and none reported any contact with livestock or farm animals.

The isolation of CC398 from individuals without any of the lineage's traditional risk factors suggests the routine transmission of this lineage in several proximate Brazilian urban areas. The isolates exhibited phenotypic and genotypic characteristics consistent with an emergent non-LA-CC398 MSSA strain that is closely related to invasive human infection (Valentin-Domelier et al. 2011, Larsen et al. 2015), suggesting that CC398 may have arrived as MSSA and acquired SCCmec in a healthcare setting. Importantly, there were no CC398 isolates in a (2006) surveillance study of cattle conducted by our group in the same geographic area (Unpublished data). Our study describes molecular virulence and resistance characteristics of several non-LA-CC398 MRSA. The intrinsic virulence features of CC398 MSSA described elsewhere and the presence of the same virulence features in the MRSA isolates described here (which are also antibiotic resistant), highlight the risk of invasive infection by these emergent strains (Valentin-Domelier et al. 2011, Larsen et al. 2015).

Given the history of the rapid spread of non-LACC398 in humans (Larsen et al. 2015), the affinity that these isolates have for the acquisition of the SCCmec cassette (Smith \& Wardyn 2015), and the lack of S. aureus epidemiological surveillance in Brazil, these findings suggest that the dissemination of CC398 in the country has been widely underreported. Underscoring this, the isolate was identified among children seeking health- 
care for reasons other than the traditional risk factors for colonisation or infection (Safdar \& Bradley 2008). We must urgently increase the quality of $S$. aureus epidemiological surveillance in Brazil, and elsewhere in Latin America, to avoid infections with other poorly molecularly and epidemiologically described isolates.

\section{ACKNOWLEDGEMENTS}

To Drs Veronica A Araujo, Eneida DV Braga, Maria TC Vieira, Cláudia A Barros and Angela CL Souza, from the Fluminense Federal University Hospital (Antônio Pedro), for their support in sample collection.

\section{AUTHORS' CONTRIBUTION}

EA, RFA and RES - Sample analysis and manuscript development; TSM and LSPA - sample analysis and PCR reactions for virulence factors; CAA - study design and manuscript preparation; FA-A - study design, sample analysis and manuscript preparation.

\section{REFERENCES}

Arriola CS, Güere ME, Larsen J, Skov RL, Gilman RH, González $\mathrm{AE}$, et al. Presence of methicillin-resistant Staphylococcus aureus in pigs in Peru. PLoS ONE. 2011; 6(12): e28529.

CLSI - Clinical and Laboratory Standards Institute. Performance standards for antimicrobial susceptibility testing: twenty-fifth informational supplement M100-S25. Wayne: CLSI; 2015.

Enright MC, Day NP, Davies CE, Peacock SJ, Spratt BG. Multilocus sequence typing for characterization of methicillin-resistant and methicillin-susceptible clones of Staphylococcus aureus. J Clin Microbiol. 2000; 38(3): 1008-15.

Gales AC, Deshpande LM, de Souza AG, Pignatari ACC, Mendes RE. MSSA ST398/t034 carrying a plasmid-mediated Cfr and Erm (B) in Brazil. J Antimicrob Chemother. 2015; 70(1): 303-5.

Iwamoto M, Mu Y, Lynfield R, Bulens SN, Nadle J, Aragon D, et al. Trends in invasive methicillin-resistant Staphylococcus aureus infections. Pediatrics. 2013; 132(4): e817-e824.

Jiménez JN, Velez LA, Mediavilla JR, Ocampo AM, Vanegas JM, Rodriguez EA, et al. Livestock-associated methicillin-susceptible Staphylococcus aureus ST398 infection in woman, Colombia. Emerg Infect Dis. 2011; 17(10): 1970-2.
Larsen J, Petersen A, Sørum M, Stegger M, van Alphen L, Valentiner-Branth P, et al. Methicillin-resistant Staphylococcus aureus $\mathrm{CC} 398$ is an increasing cause of disease in people with no livestock contact in Denmark, 1999 to 2011. Euro Surveill. 2015; 20(37): doi: 10.2807/1560-7917.ES.2015.20.37.30021.

Lima DF, Cohen RWF, Rocha GA, Albano RM, Marques EA, Leão RS. Genomic information on multidrug-resistant livestockassociated methicillin-resistant Staphylococcus aureus ST398 isolated from a Brazilian patient with cystic fibrosis. Mem Inst Oswaldo Cruz. 2017; 112(1): 79-80.

Lina G, Piémont Y, Godail-Gamot F, Bes M, Peter MO, Gauduchon $\mathrm{V}$, et al. Involvement of Panton-Valentine leukocidin-producing Staphylococcus aureus in primary skin infections and pneumonia. Clin Infect Dis. 1999; 29(5): 1128-32.

Oliveira DC, de Lencastre H. Multiplex PCR strategy for rapid identification of structural types and variants of the mec element in methicillin-resistant Staphylococcus aureus. Antimicrob Agents Chemother. 2002; 46(7): 2155-61.

Omoe K, Hu DL, Takahashi-Omoe H, Nakane A, Shinagawa K. Comprehensive analysis of classical and newly described staphylococcal superantigenic toxin genes in Staphylococcus aureus isolates. FEMS Microbiol Lett. 2005; 246(2): 191-8.

Safdar N, Bradley EA. The risk of infection after nasal colonization with Staphylococcus aureus. Am J Med. 2008; 121(4): 310-5.

Shopsin B, Gomez M, Montgomery SO, Smith DH, Waddington M, Dodge DE, et al. Evaluation of protein A gene polymorphic region DNA sequencing for typing of Staphylococcus aureus strains. J Clin Microbiol. 1999; 37(11): 3556-63.

Silva NCC, Guimarães FF, Manzi MP, Fernandes Jr A, Gómes-Sanz E, Gómez P, et al. Methicilin-resistant Staphylococcus aureus of lineage ST398 as cause of mastitis in cows. Lett Appl Microbiol. 2014; 59(6): 665-9.

Smith TC, Wardyn SE. Human infections with Staphylococcus aureus CC398. Curr Environ Health Rep. 2015; 2(1): 41-51.

Uhlemann AC, Porcella SF, Trivedi S, Sullivan SB, Hafer C, Kennedy $\mathrm{AD}$, et al. Identification of a highly transmissible animal-independent Staphylococcus aureus ST398 clone with distinct genomic and cell adhesion properties. MBio. 2012; 3(2): e00027-12.

Valentin-Domelier AS, Girard M, Bertrand X, Violette J, François P, Donnio PY, et al. Methicillin-susceptible ST398 Staphylococcus aureus responsible for bloodstream infections: an emerging human-adapted subclone? PLoS ONE. 2011; 6(12): e28369. 